\title{
Photosensitizer-induced cross-linking: A novel approach for improvement of physicochemical and structural properties of gelatin edible films
}

Taghizadeh, Masoumeh; Mohammadifar, Mohammad Amin; Sadeghi, Ehsan; Rouhi, Milad; Mohammadi, Reza; Askari, Fatemeh; Mortazavian, Amir Mohammad; Kariminejad, Mohaddeseh

\section{Published in:}

Food Research International

Link to article, DOI:

10.1016/j.foodres.2018.06.010

Publication date:

2018

Document Version

Peer reviewed version

Link back to DTU Orbit

Citation (APA):

Taghizadeh, M., Mohammadifar, M. A., Sadeghi, E., Rouhi, M., Mohammadi, R., Askari, F., Mortazavian, A. M., \& Kariminejad, M. (2018). Photosensitizer-induced cross-linking: A novel approach for improvement of physicochemical and structural properties of gelatin edible films. Food Research International, 112, 90-97. https://doi.org/10.1016/j.foodres.2018.06.010

\section{General rights}

Copyright and moral rights for the publications made accessible in the public portal are retained by the authors and/or other copyright owners and it is a condition of accessing publications that users recognise and abide by the legal requirements associated with these rights.

- Users may download and print one copy of any publication from the public portal for the purpose of private study or research.

- You may not further distribute the material or use it for any profit-making activity or commercial gain

- You may freely distribute the URL identifying the publication in the public portal 


\section{Accepted Manuscript}

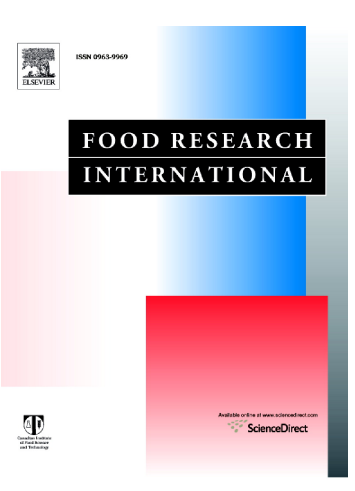

Masoumeh Taghizadeh, Mohammad Amin Mohammadifar, Ehsan Sadeghi, Milad Rouhi, Reza Mohammadi, Fatemeh Askari, Amir Mohammad Mortazavian, Mohaddeseh Kariminejad

PII: S0963-9969(18)30455-1

DOI: doi:10.1016/j.foodres.2018.06.010

Reference: FRIN 7677

To appear in: Food Research International

Received date: 29 September 2017

Revised date: 18 May 2018

Accepted date: 2 June 2018

Please cite this article as: Masoumeh Taghizadeh, Mohammad Amin Mohammadifar, Ehsan Sadeghi, Milad Rouhi, Reza Mohammadi, Fatemeh Askari, Amir Mohammad Mortazavian, Mohaddeseh Kariminejad, Photosensitizer-induced cross-linking: A novel approach for improvement of physicochemical and structural properties of gelatin edible films. Frin (2017), doi:10.1016/j.foodres.2018.06.010

This is a PDF file of an unedited manuscript that has been accepted for publication. As a service to our customers we are providing this early version of the manuscript. The manuscript will undergo copyediting, typesetting, and review of the resulting proof before it is published in its final form. Please note that during the production process errors may be discovered which could affect the content, and all legal disclaimers that apply to the journal pertain. 
Photosensitizer-ind uced cross-linking: a novel approach for improvement of physicochemical and structural properties of gelatin edible films

Masoumeh Taghizadeh ${ }^{\mathrm{a}}$, Mohammad Amin Mohammadifar ${ }^{\mathrm{b}}$, Ehs an Sadeghic, Milad Rouhic, Reza Mohammadic, Fatemeh Askari $^{\mathrm{a}}$, Amir Mohammad Mortazavian ${ }^{\mathrm{d}}$ and Mohaddeseh Kariminejad $^{\mathrm{a}}$

${ }^{\mathrm{a}}$ Students research committee, Department of Food Science and Technology, School of Nutrition Sciences and Food Technology, Kermanshah University of Medical Sciences, Kermanshah, Iran

${ }^{\mathrm{b}}$ Research Group for Food Production Engineering, National Food Institute, Technical University of Denmark, Søltofts Plads, 2800, Kgs. Lyngby, Denmark

${ }^{\mathrm{c}}$ Department of Food Science and Technology, School of Nutrition Sciences and Food Technology, Research Cent er for Environmental Determinants of Health, Kermanshah University of Medical Sciences, Kermanshah, Iran ${ }^{\mathrm{d}}$ Department of Food Science and Technology, National Nutrition and Food Technology Research Institute, Faculty of Nutrition Sciences, Food Science and Technology, Shahid Beheshti University of Medical Sciences, Iran.

*Corresponding author

P.O. Box 6719851351, Tel: +988338262052, Fax: +988338263048

Email: r.mohammadi@kums.ac.ir / r.mohammadi@sbmu.ac.ir 


\begin{abstract}
This study investigated a novel method of photosensitizer-induced cross-linking (using riboflavin as a sensitizer) to improve the structural and physicochemical properties of gelatin-based edible films with different glycerol concentrations (25\% and 50\%) during different UV exposure times (2, 4 and 6h). The films' tensile strength was enhanced significantly for both glycerol concentrations with increasing UV exposure times compared to the control film, so that the highest tensile strength was observed for films with $25 \%$ glycerol and $6 \mathrm{~h}$ of UV exposure (25\%6h). The films' tensile strength declined and the elongation at break increased about three times when the glycerol concentration was increased to $50 \%$ with $6 \mathrm{~h}$ exposure. The photosensitizerinduced cross-linking significantly reduced the films' solubility and permeability. The UVtreated films exhibited very good barrier properties against UV, with zero light transmission at a wavelength of 200 to $350 \mathrm{~nm}$. Moreover, no toxicity was found in any of the films. In addition, Fourier transform infrared spectroscopy and differential scanning calorimetry findings revealed a good interaction between functional groups of riboflavin (as the sensitizer) and gelatin in the 25\%-6h film. Therefore, this new method can be a suitable alternative to chemical methods of cross-linking biopolymers.
\end{abstract}

Keywords: Photo-oxidation, Cross-linking, Riboflavin, Gelatin edible films 


\section{Introduction}

Synthetic or non-biodegradable plastics have negative environmental impacts that are of increasing global concern (Hosseini, Rezaei, Zandi, \& Ghavi, 2013). Biodegradable packaging from renewable resources is now being used as an alternative to synthetic plastics (Costa, de Oliveira Rios, \& Flôres, 2015; Hosseini, et al., 2013). The polymers derived from biomass (biopolymer), such as proteins, polysaccharides and lipids, are the main materials used to produce edible films (Costa, et al., 2015). Gelatin is a biopolymer obtained by the partial degradation of collagen from the bones, skin and tissues of animals, under acidic-alkaline conditions (Benbettaïeb, et al., 2016; Costa, et al., 2015; Jiang, Liu, Du, \& Wang, 2010; Riquelme, Díaz-Calderón, Enrione, \& Matiacevich, 2015).

Gelatin is an abundant, low-cost material with numerous applications and functional properties in the biomedical field (Al-Hassan \& Norziah, 2012; Mohammadi, et al., 2018). It is suitable for use in the packaging industry because of its oxygen and aroma barrier properties, as well as its gelling and biodegradability properties (Divya, et al., 2018; Zhang, et al., 2010). However, it has poor mechanical properties and water resistance (Jridi, et al, 2014; Zhang, et al, 2010). Numerous procedures have been used to improve gelatin-based films' functionality, such as the use of combined films, the addition of cross-linking agents and UV exposure (Uranga, Leceta, Etxabide, Guerrero, \& de la Caba, 2016). Cross-linking is possible using enzymatic (transglutaminase), chemical (formaldehyde, glutaraldehyde) or physical (UV-C irradiation) treatments (Alves, et al, 2011; Chambi \& Grosso, 2006; Garavand, Rouhi, Razavi, Cacciotti, \& Mohammadi, 2017).

Photo-induced cross-linking is among the more effective strategies for establishing the proper interaction between biopolymers that can occur through photo-oxidation, which is carried out in 
the presence of UV, photosensitizer compounds and biopolymers. The UV exposure generates various radical compounds, such as oxygen, sensitizer and biopolymer (Cardoso, Libardi, \& Skibsted, 2012; Rich, Odlyha, Cheema, Mudera, \& Bozec, 2014). The reaction of these radical compounds creates cross-linking between the biopolymer chains, as well as between the biopolymer and the sensitizer agents. Several sensitizers, of which riboflavin (RF) is one, are used in photo-oxidation.

$\mathrm{RF}$, the water-soluble vitamin $\mathrm{B}_{2}$, is a yellow-green fluorescent compound present in a variety of food products (Sheraz, Kazi, Ahmed, Anwar, \& Ahmad, 2014). The photoproducts formed when riboflavin pigment is decomposed by light absorption also appear when the pigment is placed under UV and visible irradiation (Castillo, Criado, Díaz, \& García, 2007). Riboflavin absorbs light at wavelengths of $223,267,373$ and $444 \mathrm{~nm}$, subsequently decomposing into various products. These products could include lumiflavin (LF), lumicromum (LC), Fermi methyl flavin (FMF), carboxymethylfluanine (CMF), 2, 3-butanedione, a $\beta$-keto-acid and a diketo compound (Sheraz, et al, 2014). LF is formed under the influence of photo and alkaline $\mathrm{pH}$ on RF, whereas acidic or neutral conditions create LC (Sheraz, et al., 2014).

Many clinical studies have been conducted on the role of RF in binding biopolymers in tissue engineering, transplantation and corneal rejuvenation (Mencucci, et al., 2013; Tirella, Liberto, \& Ahluwalia, 2012). However, no studies have been performed on the effects of photo-oxidation on the functional properties and probable toxic compounds of edible films. The objectives of this study were to examine the effects of photo-oxidation in the presence of riboflavin as a sensitizer on the physicochemical, structural and cytotoxicological properties of edible gelatin film.

\section{Materials and methods}




\subsection{Materials}

Fish gelatin (bloom number $~ 240-270$, water $\leq 12 \%$ ) was purchased from Biobasic (Markham, Canada). Riboflavin was purchased from the Zahravi Company (Tehran, Iran). Glycerol was purchased from Merck Chemicals Co. (Darmstadt, Germany). Collagenase II was purchased from Sigma (St. Louis, MO, USA). Penicillin/streptomycin was purchased from Gibco (Carlsbad, CA).

\subsection{Preparation of the films}

The preparation of gelatin films followed the procedures of Jridi et al. (2013) with modification. Firstly, a gelatin solution was prepared by mixing $4 \mathrm{~g}$ of gelatin with $100 \mathrm{ml}$ of distilled water under continuous stirring at $45^{\circ} \mathrm{C}$ for $30 \mathrm{~min}$. Secondly, $0.05 \mathrm{~g}$ riboflavin $(1.25 \% \mathrm{w} / \mathrm{w}$ based on gelatin) was dissolved in distilled water at $55^{\circ} \mathrm{C}$ for $30 \mathrm{~min}$ until a completely monotonic solution was achieved. The riboflavin solution was slowly added to the gelatin solution and mixed at $45^{\circ} \mathrm{C}$ for $15 \mathrm{~min}$. Thirdly, glycerol was added as a plasticizer at concentrations of 0,25 and $50 \%$ (w/w based on gelatin), and the film-forming solutions (FFS) were stirred at $45^{\circ} \mathrm{C}$ for $15 \mathrm{~min}$ to achieve a homogeneous solution. The $\mathrm{pH}$ of the FFS was adjusted to 6.5 using $\mathrm{HCl}$. Fifty milliliters of the solution were poured into Petri dishes of $15 \mathrm{~cm}$ diameter. The samples were exposed to UV light at $260 \mathrm{~nm}$ (HNS 8W, Italy) and a distance of $5 \mathrm{~cm}$ for a period of 2, 4 and $6 \mathrm{~h}$. Films were completely dried at $25^{\circ} \mathrm{C}$ and a relative humidity $(\mathrm{RH})$ of $40 \pm 2 \%$ for $48 \mathrm{~h}$, then peeled off the plate surface. The samples were conditioned in a desiccator containing saturated magnesium nitrate $\left(25 \pm 3^{\circ} \mathrm{C}-53 \% \mathrm{RH}\right)$ for $72 \mathrm{~h}$ before their physicochemical and structural properties were tested. Gelatin films containing $25 \%$ glycerol without both UV and riboflavin (25\%-no UV \& RF) and $25 \%$ glycerol with UV and without RF were considered as the control films. All treatments were made in triplicate. 


\subsection{Film thickness}

The thickness of each sample was measured by averaging the measurements from nine positions using a micrometer (Mitutoyo Manufacturing Corporation, Tokyo, Japan) with $0.001 \mathrm{~mm}$ accuracy.

\subsection{Moisture content}

After the initial weight, the film samples $(2 \mathrm{~cm} \times 2 \mathrm{~cm})$ were dried in an oven at $105 \pm 1{ }^{\circ} \mathrm{C}$ until they reached constant weight, then weighed again. The samples' moisture contents were measured in triplicate. The moisture of the films was calculated using equation (1):

$W C=\frac{w_{1}-w_{2}}{w_{1}} \times 100(1)$

where $\mathrm{W}_{1}$ is the initial weight and $\mathrm{W}_{2}$ is the secondary weight after oven-drying.

\subsection{Water-vapor permeability}

Water-vapor permeability (WVP) was determined using the ASTM E96-05 standard method (ASTM, 2005). Circular glass test cups with an internal diameter of $4 \mathrm{~cm}$ and a height of $10 \mathrm{~cm}$ were filled with anhydrous calcium chloride (15 g). Then the cups were covered and placed in a desiccator containing saturated $\mathrm{NaCl}$ solution at $25^{\circ} \mathrm{C}(0 \% \mathrm{RH}, 0 \mathrm{~Pa}$ water-vapor pressure). The water was transferred along the film surface, adsorbed by the calcium chloride. The cups were weighed at $24 \mathrm{~h}$ intervals over seven days. The slope of mass loss versus time was calculated with a linear regression of $r^{2} \geq 0.99$. The WVP of the films was calculated using equation (2):

$W V P=\frac{W \times X}{t \times A \times \Delta P}$

where $\mathrm{W}$ is the weight change $(\mathrm{g}), \mathrm{X}$ is the mean thickness of film $(\mathrm{m}), \mathrm{A}$ is the film area $\left(\mathrm{m}^{2}\right), \mathrm{t}$ is time (s) and $\Delta \mathrm{P}$ is the difference of vapor pressure across the film $(\mathrm{Pa})$. 


\subsection{Water solubility}

Gelatin film samples $(3 \mathrm{~cm} \times 2 \mathrm{~cm})$ were weighed and placed in dishes containing $50 \mathrm{ml}$ of distilled water and stirred at $25^{\circ} \mathrm{C}$ for $24 \mathrm{~h}$. Undissolved debris was filtered out using filter paper, and the paper was dried at $105^{\circ} \mathrm{C}$ for $1 \mathrm{~h}$. The solubility of the films was calculated using equation (3):

Solubility $=\frac{\mathrm{w}_{1}-\mathrm{w}_{2}}{\mathrm{w}_{1}} \times 100$

where $\mathrm{W}_{1}$ is the initial weight and $\mathrm{W}_{2}$ is the weight of the undissolved film after drying.

\subsection{Mechanical properties}

Mechanical properties were determined using ASTM D882-91 (Tongdeesoontorn, Mauer, Wongruong, Sriburi, \& Rachtanapun, 2012) with a texture analyzer (SMT-20, Santam, Tehran, Iran). The films were placed in the desiccator for $48 \mathrm{~h}$ at $50 \pm 5 \% \mathrm{RH}$ at $25^{\circ} \mathrm{C}$. The tensile strength $(\mathrm{TS})$ and percentage of elongation at break $(\mathrm{EAB})$ of the film samples $(1 \mathrm{~cm} \times 10 \mathrm{~cm})$ were measured at a cross-head speed of $10 \mathrm{~mm} / \mathrm{min}$ with an initial grip length of $5 \mathrm{~cm}$. The tests were performed in triplicate and the average of the results was calculated for each film.

\subsection{Fourier transform infrared spectroscopy measurement}

To obtain the films' Fourier transform infrared (FTIR) spectroscopy spectra, each sample was placed into the spectroscope's crystal cell, which was mounted on an FTIR spectrometer (Shimadzu Irprestige-21, Japan). The FTIR spectra were obtained using an attenuated total reflection (ATR) accessory in the range of 500 to $4000 \mathrm{~cm}^{-1}$ at a resolution of $4 \mathrm{~cm}^{-1}$ with 32 scans, and the data were controlled against a background spectrum. The rectangular film samples were placed directly onto the spectrophotometer cell. 


\subsection{Differential scanning calorimetry (DSC)}

The film samples were conditioned in desiccators with silica gel to dehydrate them for at least three weeks. The thermal properties of the samples were assessed using a differential scanning calorimeter (DSC 822e, Mettler Toledo, Switzerland). Samples of about $10 \mathrm{mg}$ were weighed and encapsulated in aluminum pans individually and heated at a rate of $10^{\circ} \mathrm{C} / \mathrm{min}$ under a nitrogen flow of $10 \mathrm{~cm}^{3} / \mathrm{min}$ at a temperature range of -20 to $150^{\circ} \mathrm{C}$. An empty aluminum pan was used as a reference.

\subsection{Light transmission and transparency}

Initially the films were cut and placed in the test cell of a UV-visible spectrophotometer (S2100SUV, UNICO, Shanghai) that was calibrated using an empty test cell. The films' light transmission was measured in wavelengths between 200 and $800 \mathrm{~nm}$. The transparency value was determined using equation (4):

Transparency value $=\frac{-\log \mathrm{T}_{600}}{\mathrm{x}}$

where $\mathrm{T}_{600}$ is the transmittance at $600 \mathrm{~nm}$ and $\mathrm{x}$ is the film thickness (mm). According to the equation, the higher the transparency value, the lower the films' transparency.

\subsection{Cytotoxicity test}

\subsubsection{Cell culture}

The viability of the human adipose tissue-derived mesenchymal stem cells (hADSCs) and NIH $3 \mathrm{~T} 3$ cells (mouse embryonic fibroblast cell line) seeded on the gelatin membrane was determined by MTT assay. NIH 3T3 fibroblasts were obtained from the Pasteur Institute of Iran (Tehran, Iran) and expanded in Dulbecco's modified Eagle's medium (DMEM) supplemented with 10\% 
fetal bovine serum (FBS) and 1\% penicillin/streptomycin. The cells were sub-cultured when they reached 90\% confluence. NIH 3 T3 in passage 3 was used in this study (Rostami, et al., 2015).

The hADSCs were isolated from human adipose tissue collected after elective liposuction surgery according to procedures approved by the Ethics Committee at Shahid Beheshti University of Medical Sciences, Tehran, Iran (Gholipourmalekabadi, et al., 2016). Briefly, the tissues were rinsed twice with phosphate-buffered saline supplemented with antibiotics and antifungals, and then treated with $0.2 \%$ collagenase II for 30 minutes at $37{ }^{\circ} \mathrm{C}$. The samples were centrifuged and the supernatant was discarded. The cell pellet was resuspended in DMEM, supplemented with $10 \%$ FBS and $1 \%$ penicillin/streptomycin by micro-pipetting and seeded in two T-75 $\mathrm{cm}^{2}$ - cell culture flasks. The cell medium was changed every three days. After reaching $80 \%$ confluence, the cells were sub-cultured using trypsin/ethylene diamine tetra-acetic acid (EDTA). The cells of the second passage were used in this study.

\subsubsection{MTT assay}

Cell viability was determined based on the ability of the living cells' mitochondria to reduce the level of tetrazolium salt (MTT [3-(4, 5-dimethyl-2-thiazoly)-2, 5-diphenyl-2H-tetrazolium bromide]). MTT assay was carried out by a slightly modified procedure described previously (Samadikuchaksaraei, et al, 2016). For this purpose, $2 \times 10^{4}$ cells were gently seeded on the 25\%-6h treatment $(1 \mathrm{~cm} \times 1 \mathrm{~cm})$, feed with a supplemented DMEM (described above) and incubated in a humidified atmosphere of air and $5 \% \mathrm{CO}_{2}$ at $37^{\circ} \mathrm{C}$ for $1,2,3,7$ and 14 days. After each interval, the cells were treated with $10 \%$ MTT solution for $2 \mathrm{~h}$. The cells were then washed with phosphate-buffered saline and treated with dimethyl sulfoxide (DMSO). The optical density of the samples was measured with an ELISA (enzyme-linked immunosorbent assay) reader at a 
wavelength of $590 \mathrm{~nm}$. The cells cultured on the plastic surface of the cell culture flask served as a negative control, which was considered to be $100 \%$ cell viability.

\subsection{Statistical analysis}

The statistical analysis was conducted using one-way analysis of variance (ANOVA) using SPSS software (version 23.0, SPSS Inc., Chicago, USA). A Duncan's multiple range test method was employed to detect significant $(\mathrm{p}<0.05)$ differences.

\section{Results and discussion}

\subsection{Solubility}

Due to the hydrophilic properties of proteins (which are in turn due to the presence of polar peptides), gelatin films are highly soluble in water; this is a limitation on their use for packaging applications (Mohajer, Rezaei, \& Hosseini, 2017). The solubility values of film samples are showed in table 1.For the film samples at the $25 \%$ glycerol concentration, solubility was decreased by increasing UV exposure time from 2 to $6 \mathrm{~h}$. However, the greatest solubility reduction $(30.66 \%$, significantly lower than the control film) was observed for treatment $25 \%$ 4h. This could be due to the interaction between the functional groups in gelatin and the riboflavin as a sensitizer, which acts as a physical barrier to prevent the penetration of water into the gelatin film network. However, the values for the solubility of films for all treatments containing $25 \%$ glycerol were less than half of those found in other studies on gelatin films. The obtained quantities were lower than the results reported by Hosseini et al. (Hosseini, et al, 2013) and Núñez-Flores et al. (Núñez-Flores, et al., 2012) for gelatin films made from the skin of coldwater fish $(\sim 63.81 \%)$ and from cod skin $(\sim 92 \%)$. Moreover, values for solubility in the present 
study were lower than those found for gelatin films containing cross-linking agents such as transglutaminase (Chambi, et al., 2006) and glutaraldehyde (Alves, et al., 2011).

Film solubility increased with an increase in glycerol concentration from $25 \%$ to $50 \%$. However, the UV exposure times had significant effects on the solubility of films containing $50 \%$ gelatin. Glycerol, due to its high hydrophilicity, can lead to increased water absorption, which causes the film structure to unfold and increases the film solubility. However, the solubility of films in all treatments containing 50\% glycerol were less than that found in previous studies. This difference could be due to the cross-linking effect of the phototoxidation mechanism, which caused part of the glycerol to participate in the film structure, resulting in a decrease in its hydrophilic ity.

\subsection{Water-vapor permeability}

The WVP of edible film mainly depends on the structure of its polymers, its thickness and its molecular weight (Jridi, Souissi, et al., 2013; Li, Miao, Wu, Chen, \& Zhang, 2014). Table 1 presents the degree of WVP in the photosensitizer-treated gelatin films and the control gelatin film. The results showed that the treated films had a dramatically significant relationship with WVP compared to the control film. Many protein-based edible films, particularly those made with gelatin, increase WVP due to their non-linear and complex structure and their long-chain and high-hydrophilic groups (Etxabide, Urdanpilleta, de la Caba, \& Guerrero, 2016). The photosensitizer-treated gelatin films reduced the free spaces between the polymer matrix and the amount of hydrophilic amino acids on the film surface due to the different cross-links between gelatin-riboflavin-gelatin and gelatin-gelatin, resulting in a stronger film structure and less permeability by water molecules through the polymer.

Increasing the UV exposure times decreased the WVP for both glycerol concentrations. The lowest value for all treatments was found for the treatment $25 \%-6 \mathrm{~h}(3.12)$. This was a lower 
WVP, significantly different from the values found for gelatin films cross-linked with transglutaminase $\left(0.066 \times 10-8 \mathrm{~g} \times(\mathrm{m} \times \mathrm{s} \times \mathrm{Pa})^{-1}\right)($ Kołodziejska \& Piotrowska, 2007), glutaraldehyde $\left(0.020 \times 10^{-8} \mathrm{~g} \times(\mathrm{m} \times \mathrm{s} \times \mathrm{Pa})^{-1}\right.$ (Chiou, et al., 2008) and nano-chitin $\left(8.89 \times 10^{-}\right.$ ${ }^{10} \mathrm{~g} \times(\mathrm{m} \times \mathrm{s} \times \mathrm{Pa})^{-1}($ Sahraee, Milani, Ghanbarzadeh, \& Hamishehkar, 2017). However, the WVP was higher than that found for films containing cross-linking agents such as tannin acid $\left(6.7 \times 10^{-13} \mathrm{~g} \times(\mathrm{m} \times \mathrm{s} \times \mathrm{Pa})^{-1}\right.$ and ferulic acid $\left(5.5 \times 10^{-13} \mathrm{~g} \times(\mathrm{m} \times \mathrm{s} \times \mathrm{Pa})^{-1}(\mathrm{Cao}, \mathrm{Fu}, \& \mathrm{He}\right.$, 2007). This difference can be attributed to the nature of the polymers and the type and concentrations of the cross-linking agents. The WVP was greater in all treatments at the 50\% glycerol concentration relative to the $25 \%$ glycerol concentration. This trend is in line with other studies of plasticizer concentration, probably because of the increased mobility and further spaces between the polymers imparted by the plasticizer. Such results have also been confirmed in tests of the films' mechanical properties.

\subsection{Mechanical properties}

Mechanical properties were usually related to the films' intermolecular force and network microstructure (Table 1). The tensile strength increased significantly from 18.7 to $77.8 \mathrm{MPa}$ by increasing the photo-oxidation time from 2 to $6 \mathrm{~h}$ at the $25 \%$ glycerol concentration. Furthermore, the tensile strength of the $25 \%-6 \mathrm{~h}$ treatment was about eight times greater than that of the control sample. The results show higher tensile strength for the photosensitizer-treated gelatin films in comparison to many gelatin films produced with cross-linking agents.

These findings suggest that UV in the presence of a riboflavin sensitizer increases films' tensile strength by forming gelatin-gelatin and gelatin-riboflavin-gelatin polymer cross-links. Previous studies reported different results regarding the effect of radiation on films' mechanical properties. Sionkowska et al. (2006) stated that the tensile strength was reduced due to the 
breakdown of peptide bonds through increasing UV exposure time in the collagen film (380 nm). However, Benbettaïeb et al. (2016) reported that electron-beam irradiation increases the tensile strength of gelatin films. The difference in these results may be due to differences in the radiation conditions and the film-production methods.

With an increase in the concentration of glycerol from $25 \%$ to $50 \%$, the films' TS decreased and EAB increased. For the films at the $50 \%$ glycerol concentration, the TS was enhanced by increasing the UV exposure time from 2 to $6 \mathrm{~h}$; the TS was significantly different from that of the control treatment.

In all photosensitizer-treated gelatin films, the $\mathrm{EAB}$ percentage was improved compared to the control film regardless of the duration of the UV exposure. The $25 \%-6 \mathrm{~h}$ and the $50 \%-2 \mathrm{~h}$ treatments showed the lowest $(44.0 \%)$ and highest (154.6\%) EAB values among photosensitizertreated films, respectively. Compared to previous studies, the EAB and TS values were higher for gelatin films at the same glycerol concentration (Cerqueira, Souza, Teixeira, \& Vicente, 2012; Hanani, McNamara, Roos, \& Kerry, 2013). This may be due to the interaction between gelatin chains caused by the photo-oxidation mechanism.

\subsection{FTIR-ATR analysis}

FTIR spectroscopy was performed to evaluate the possible cross-linked interactions of films due to UV radiation. As shown in Fig. 1, the FTIR spectra of neat gelatin film indicate the characteristic absorption bands at $3275 \mathrm{~cm}^{-1}, 2927 \mathrm{~cm}^{-1}, 1631 \mathrm{~cm}^{-1}, 1539 \mathrm{~cm}^{-1}$ and $1234 \mathrm{~cm}^{-1}$, corresponding to the $\mathrm{NH}$ stretching coupled with hydrogen bonding from amide- $\mathrm{A} ; \mathrm{NH}_{3}{ }^{+}$ bending and $\mathrm{C}-\mathrm{H}$ stretching from amide $\mathrm{B} ; \mathrm{C}=\mathrm{O}$ stretching/hydrogen bonding (coupled with $\mathrm{COO}$ ) from amide-I; $\mathrm{N}-\mathrm{H}$ bending and $\mathrm{C}-\mathrm{N}$ stretching from amide-II; and $\mathrm{C}-\mathrm{N}$ and $\mathrm{N}-\mathrm{H}$ in-plane stretching or $\mathrm{CH}_{2}$ vibrations of glycine from amide-III, respectively (Aewsiri, Benjakul, \& 
Visessanguan, 2009; Hoque, Benjakul, \& Prodpran, 2011; Muyonga, Cole, \& Duodu, 2004a, 2004b). According to Muyonga et al. (Muyonga, et al., 2004b), the amide I absorption band between 1600 and $1700 \mathrm{~cm}^{-1}$ is a useful peak for FTIR analysis of the secondary structure of proteins like gelatin. Spectra of different samples revealed significant changes among the functional groups. The peaks' intensity under UV radiation in films without a riboflavin sensitizer (25\%-6h-no RF) were higher than for the control film. Moreover, UV radiation caused an increase in the wavenumber of the amide A, II and III bands, probably due to stimulation of the crosslinking reaction among functional groups of gelatin by UV rays. Contrary to these results, Sionkowska reported that solar UV radiation of collagen films resulted in the scission of hydrogen bonds and a shift of the amide A and I bands to lower wavenumbers (Sionkowska, 2006). The difference in results could be due to the type of biopolymers, the wavelength of UV rays and/or other experimental conditions.

The intensity of FTIR spectra peaks decreased with the addition of riboflavin as a photosensitizer and UV irradiation (treatment 25\%-6h) compared to treatment 25\%-6h-no RF. However, the intensity of the amide A, B, I and II bands was higher than that for the control film. These results showed that riboflavin and UV irradiation in treatment $25 \%-6 \mathrm{~h}$ resulted in fewer amide bonds than treatment 25\%-6h-no RF, and more amide bonds (except for amide III) than for the control film. However, the presence of the photosensitizer in UV-radiated film caused an increase in the intensity of the band at $\sim 1276 \mathrm{~cm}^{-1}$ (probably related to diarylamines). Moreover, a new drastic dip at 1700-2000 $\mathrm{cm}^{-1}$ was formed in the presence of both the photosensitizer and glycerol in UV-radiated gelatin film. These changes could be due to photo-oxidation mechanisms and cross-linking of gelatin functional groups, especially the cross-linking of aromatic amino acids (tyrosine and phenylalanine) with the $\mathrm{N}$ and $\mathrm{C}-\mathrm{O}$ groups of excited 
riboflavin and glycerol, respectively. Fig. 2 shows the main possible interactions resulting from photo-oxidation in edible gelatin films. These results confirmed those from the examination of mechanical properties.

Plasticizer concentration is an important factor in film structure. A new method for film preparation was used in this study. Therefore, it was necessary to investigate the effects of glycerol on the films' FTIR spectra. Uranga et al. (2016) reported that the typical absorption bands of glycerol are located in the range of 800 to $1150 \mathrm{~cm}^{-1}$, which is associated with the vibrations of $\mathrm{C}-\mathrm{C}$ and $\mathrm{C}-\mathrm{O}$ bonds. Figure 1 shows that the intensity of the main typical glycerol spectrum peaks decreased in treatment $25 \%-6 \mathrm{~h}$ compared to $0 \%-6 \mathrm{~h}$, probably due to new interactions of glycerol and the formation of a new drastic dip at $1700-2000 \mathrm{~cm}^{-1}$. The intensity of these peaks increased in treatment 50\%-6h. Similarly, Hanani et al. (Hanani, et al., 2013) and Núñez-Flores et al. (Núñez-Flores, et al., 2013) reported an increase in the peak intensity at 1033 $\mathrm{cm}^{-1}$ related to the presence of glycerol; this may be due to extra interactions between the glycerol and film structure. Moreover, the wavenumber of amide A decreased and that of the II bands increased with increasing glycerol concentration. These variations probably indicate an increase in the number of chemical bonds and interactions between UV-excited glycerol (C-O) and stimulated functional groups of gelatin and/or riboflavin.

\subsection{Thermal properties}

The thermal properties of polymers are significant in determining their usefulness as a packaging material. It is important to study their heat stability during preparation, processing or consumption in the packaging industry (Jridi, Nasri, et al, 2013). DSC thermograms, partially verified by FTIR findings (Fig. 3), were used to investigate the cross-link reactions in the UVtreated films. In gelatin films, the melting transition temperature is associated with the helix-coil 
transition during gelatin denaturation compared to the native status. The helix-coil transition revealed the disappearance of hydrogen bonds in the triple helix and the rearrangement of the gelatin skeleton (Alves, et al., 2011). Therefore, the melting enthalpy $\left(\Delta \mathrm{H}_{\mathrm{m}}\right)$ has a direct relation to the value of the triple helix in the film matrix (Chambi, et al., 2006). One of the important factors in the thermal stability of gelatin films is the amount of proline and hydroxyproline amino acids in the gelatin triple-helical structure, which is different in various references. In the current study, the melting point was higher for the UV-treated films than for the control sample. This may be due to the formation of further intramolecular and intermolecular hydrogen and covalent bonds by exciting the functional groups of riboflavin and gelatin during photooxidation. The melting point obtained in treatments under UV radiation was higher than the result obtained by $\mathrm{Ma}$ et al. (Ma, et al., 2012). The melting point was elevated by increasing UV exposure time in both glycerol concentrations to $108.22^{\circ} \mathrm{C}$ for the $25 \%$ - 6 h treatment and $73.25^{\circ} \mathrm{C}$ for the 50\%-6h treatment. The melting point was decreased by increasing the glycerol concentrations from $25 \%$ to $50 \%$, possibly due to the partial inhibitory effect of glycerol on the formation of protein structures. Generally, the results of mechanical properties, DSC and FTIR showed the proper interaction between gelatin and riboflavin.

\subsection{Light transmission and transparency}

The amount of light transmission in food packing is considered to be a key factor in maintaining the quality of coated foodstuffs. Light transmission (especially in the UV wavelengths) causes food discoloration, reduced nutritional value, auto-oxidation and other undesirable chemical reactions in packaged foods (Hosseini, et al, 2013). The results of the current study showed that the amount of UV light transmission was zero in all UV-treated samples at the wavelength range of 200 to $350 \mathrm{~nm}$. Previous studies on gelatin films have reported that the amount of light 
transmission up to $350 \mathrm{~nm}$ was less than $50 \%$. The main reason for this great difference can be UV absorption through riboflavin amide rings in the gelatin films' composition. However, it has been found that less light is transmitted through gelatin films due to the presence of cyclic amino acids (tyrosine and tryptophan) than through other protein films (Mohammadi, et al., 2018). The amount of light transmission was enhanced significantly in the current study by increasing the wavelength from 400 to $800 \mathrm{~nm}$. One of the other optical features of edible films is their transparency index, with a higher transparency index indicating greater opacity. As shown in Table 2, there was no significant difference in transparency index between any of the photosensitizer-treated gelatin films. The transparency index depends on the internal structure of the films, indicating proper interaction between polymers. In general, the photosensitizer-treated gelatin films were an effective barrier against UV light, which is a crucial characteristic in food packaging.

\subsection{Cytotoxicity}

According to previous studies, chemical cross-linking agents such as glutaraldehyde, boric acid, ethylene glycol diglycidyl ether, ammonium zirconium carbonate and $\mathrm{H}_{2} \mathrm{SO}_{4}$ can improve the mechanical properties and water resistance of edible films (Garavand, et al., 2017). Nevertheless, residues of unreacted cross-linking agents and their interaction between polymers could be a source of toxicity. This study has examined a new method for the formation of cross-links between biopolymers using UV light and a sensitizing agent in gelatin films; therefore it was essential to investigate the toxicity of the films. Fig. 4 shows the cytotoxicity results for the gelatin films in the current study. Light-microscope photographs of the hADSCs and NIH 3T3 are shown in Fig. 4A, and the MTT results are shown in Fig. 4B. The microscopic results in passage 3 proved the presence of the spindly cells of the hADSCs and NIH 3T3. The MTT assay 
measures the cell's capacity to reduce MTT, and is therefore a direct measurement of cell viability. Only cells that are metabolically healthy and normal can convert tetrazolium salt into purple crystals (Draye, et al., 1998). The more active and numerous the cells, the more intense the color created (Manna, et al., 2015). MTT results showed that UV-treated films (25\%-6h, 0.05 g riboflavin) did not change the average viability of either cell types during incubation for 14 days $(\mathrm{p}>0.05)$. Therefore, films produced by photo-oxidation were non-toxic and biocompatible with mesenchymal and fibroblast cells.

\section{Conclusion}

The results of this study showed that the mechanical properties of gelatin-based films were significantly improved by increasing the UV exposure time up to $6 \mathrm{~h}$, and the films' WVP and solubility were decreased. Following an increase in glycerol concentration from $25 \%$ to $50 \%$, solubility, WVP and EAB were increased and the film TS was decreased. The physicochemical indices of all films showed remarkable improvement compared to the control film, which indicated that this new method incorporated a percentage of glycerol in the film structure and reduced its barrier role. The structural characteristics (as measured by FTIR and DSC) and the physicochemical properties of the films showed that the $25 \%$ - $6 \mathrm{~h}$ and $50 \%$ - $6 \mathrm{~h}$ films among all treatments were suitable films, depending on their various applications. This new method, which enhances the interaction between polymers by forming cross-links between different functional groups, requires further research into the interaction between polymers and various natural sensitizers, as their lack of toxicity suggests that they can serve as alternatives to other chemical cross-linking methods. 


\section{Acknowledgments}

We are thankful to the Department of Food Science and Technology, Kermanshah University of Medical Sciences, for its support of this study [Grant number: 95391].

\section{Conflict of Interest}

The authors declare that there are no conflicts of interest. 


\section{References}

Aewsiri, T., Benjakul, S., \& Visessanguan, W. (2009). Functional properties of gelatin from cuttlefish (Sepia pharaonis) skin as affected by bleaching using hydrogen peroxide. Food Chemistry, 115(1), 243-249.

Al-Hassan, A., \& Norziah, M. (2012). Starch-gelatin edible films: Water vapor permeability and mechanical properties as affected by plasticizers. Food Hydrocolloids, 26(1), 108-117.

Alves, P. M., Carvalho, R. A., Moraes, I. C., Luciano, C. G., Bittante, A. M. Q., \& Sobral, P. J. (2011). Development of films based on blends of gelatin and poly (vinyl alcohol) cross linked with glutaraldehyde. Food Hydrocolloids, 25(7), 1751-1757.

ASTM. (2005). Standard test method for water vapor transmission of materials (E 96-05). In: Annual Book of ASTM Standards. American Society for Testing Materials, Philadelphia, $P A$.

Benbettaïeb, N., Chambin, O., Assifaoui, A., Al-Assaf, S., Karbowiak, T., \& Debeaufort, F. (2016). Release of coumarin incorporated into chitosan-gelatin irradiated films. Food hydrocolloids, 56, 266-276.

Cao, N., Fu, Y., \& He, J. (2007). Mechanical properties of gelatin films cross-linked, respectively, by ferulic acid and tannin acid. Food Hydrocolloids, 21(4), 575-584.

Cardoso, D. R., Libardi, S. H., \& Skibsted, L. H. (2012). Riboflavin as a photosensitizer. Effects on human health and food quality. Food \& Function, 3(5), 487-502.

Castillo, C., Criado, S., Díaz, M., \& García, N. A. (2007). Riboflavin as a sensitiser in the photodegradation of tetracyclines. Kinetics, mechanism and microbiological implications. Dyes and Pigments, 72(2), 178-184.

Chambi, H., \& Grosso, C. (2006). Edible films produced with gelatin and casein cross-linked with transglutaminase. Food Research International, 39(4), 458-466.

Chiou, B.-S., Avena-Bustillos, R. J., Bechtel, P. J., Jafri, H., Narayan, R., Imam, S. H., Glenn, G. M., \& Orts, W. J. (2008). Cold water fish gelatin films: Effects of cross-linking on thermal, mechanical, barrier, and biodegradation properties. European Polymer Journal, 44(11), 3748-3753.

Costa, T. M. H., de Oliveira Rios, A., \& Flôres, S. H. (2015). Residues of minimally processed carrot and gelatin capsules: potential materials for packaging films. Industrial Crops and Products, 76, 1071-1078.

Divya, M., Vaseeharan, B., Abinaya, M., Vijayakumar, S., Govindarajan, M., Alharbi, N. S., Kadaikunnan, S., Khaled, J. M., \& Benelli, G. (2018). Biopolymer gelatin-coated zinc oxide nanoparticles showed high antibacterial, antibiofilm and anti-angiogenic activity. Journal of Photochemistry and Photobiology B: Biology, 178, 211-218.

Draye, J.-P., Delaey, B., Van de Voorde, A., Van Den Bulcke, A., De Reu, B., \& Schacht, E. (1998). In vitro and in vivo biocompatibility of dextran dialdehyde cross-linked gelatin hydrogel films. Biomaterials, 19(18), 1677-1687.

Etxabide, A., Urdanpilleta, M., de la Caba, K., \& Guerrero, P. (2016). Control of cross-linking reaction to tailor the properties of thin films based on gelatin. Materials Letters, 185, 366-369.

Garavand, F., Rouhi, M., Razavi, S. H., Cacciotti, I., \& Mohammadi, R. (2017). Improving the integrity of natural biopolymer films used in food packaging by crosslinking approach: A review. International Journal of Biological Macromolecules. 
Gholipourmalekabadi, M., Sameni, M., Radenkovic, D., Mozafari, M., Mossahebi-Mohammadi, M., \& Seifalian, A. (2016). Decellularized human amniotic membrane: how viable is it as a delivery system for human adipose tissue-derived stromal cells? Cell Proliferation, 49(1), 115-121.

Hanani, Z. N., McNamara, J., Roos, Y., \& Kerry, J. (2013). Effect of plasticizer content on the functional properties of extruded gelatin-based composite films. Food Hydrocolloids, 31(2), 264-269.

Hoque, M. S., Benjakul, S., \& Prodpran, T. (2011). Properties of film from cuttlefish (Sepia pharaonis) skin gelatin incorporated with cinnamon, clove and star anise extracts. Food Hydrocolloids, 25(5), 1085-1097.

Hosseini, S. F., Rezaei, M., Zandi, M., \& Ghavi, F. F. (2013). Preparation and functional properties of fish gelatin-chitosan blend edible films. Food Chemistry, 136(3-4), 14901495.

Jiang, M., Liu, S., Du, X., \& Wang, Y. (2010). Physical properties and internal microstructures of films made from catfish skin gelatin and triacetin mixtures. Food Hydrocolloids, 24(1), 105-110.

Jridi, M., Hajji, S., Ayed, H. B., Lassoued, I., Mbarek, A., Kammoun, M., Souissi, N., \& Nasri, M. (2014). Physical, structural, antioxidant and antimicrobial properties of gelatinchitosan composite edible films. International Journal of Biological Macromolecules, 67, 373-379.

Jridi, M., Nasri, R., Lassoued, I., Souissi, N., Mbarek, A., Barkia, A., \& Nasri, M. (2013). Chemical and biophysical properties of gelatins extracted from alkali-pretreated skin of cuttlefish (Sepia officinalis) using pepsin. Food Research International, 54(2), 16801687.

Jridi, M., Souissi, N., Mbarek, A., Chadeyron, G., Kammoun, M., \& Nasri, M. (2013). Comparative study of physico-mechanical and antioxidant properties of edible gelatin films from the skin of cuttlefish. International Journal of Biological Macromolecules, 61, $17-25$.

Kołodziejska, I., \& Piotrowska, B. (2007). The water vapour permeability, mechanical properties and solubility of fish gelatin-chitosan films modified with transglutaminase or 1-ethyl-3(3-dimethylaminopropyl) carbodiimide (EDC) and plasticized with glycerol. Food Chemistry, 103(2), 295-300.

Li, J.-H., Miao, J., Wu, J.-L., Chen, S.-F., \& Zhang, Q.-Q. (2014). Preparation and characterization of active gelatin-based films incorporated with natural antioxidants. Food Hydrocolloids, 37, 166-173.

Ma, W., Tang, C.-H., Yin, S.-W., Yang, X.-Q., Wang, Q., Liu, F., \& Wei, Z.-H. (2012). Characterization of gelatin-based edible films incorporated with olive oil. Food Research International, 49(1), 572-579.

Manna, P. J., Mitra, T., Pramanik, N., Kavitha, V., Gnanamani, A., \& Kundu, P. (2015). Potential use of curcumin loaded carboxymethylated guar gum grafted gelatin film for biomedical applications. International Journal of Biological Macromolecules, 75, 437446.

Mencucci, R., Paladini, I., Sarchielli, E., Favuzza, E., Vannelli, G. B., \& Marini, M. (2013). Transepithelial riboflavin/ultraviolet. A corneal cross-linking in keratoconus: morphologic studies on human corneas. American Journal of Ophthalmology, 156(5), 874-884. e871. 
Mohajer, S., Rezaei, M., \& Hosseini, S. F. (2017). Physico-chemical and microstructural properties of fish gelatin/agar bio-based blend films. Carbohydrate Polymers, 157, 784793.

Mohammadi, R., Mohammadifar, M. A., Rouhi, M., Kariminejad, M., Mortazavian, A. M., Sadeghi, E., \& Hasanvand, S. (2018). Physico-mechanical and structural properties of eggshell membrane gelatin-chitosan blend edible films. International Journal of Biological Macromolecules, 107, 406-412.

Muyonga, J., Cole, C., \& Duodu, K. (2004a). Characterisation of acid soluble collagen from skins of young and adult Nile perch (Lates niloticus). Food Chemistry, 85(1), 81-89.

Muyonga, J., Cole, C., \& Duodu, K. (2004b). Fourier transform infrared (FTIR) spectroscopic study of acid soluble collagen and gelatin from skins and bones of young and adult Nile perch (Lates niloticus). Food Chemistry, 86(3), 325-332.

Núñez-Flores, R., Giménez, B., Fernández-Martín, F., López-Caballero, M., Montero, M., \& Gómez-Guillén, M. (2012). Role of lignosulphonate in properties of fish gelatin films. Food Hydrocolloids, 27(1), 60-71.

Núñez-Flores, R., Giménez, B., Fernández-Martín, F., López-Caballero, M., Montero, M., \& Gómez-Guillén, M. (2013). Physical and functional characterization of active fish gelatin films incorporated with lignin. Food Hydrocolloids, 30(1), 163-172.

Rich, H., Odlyha, M., Cheema, U., Mudera, V., \& Bozec, L. (2014). Effects of photochemical riboflavin-mediated crosslinks on the physical properties of collagen constructs and fibrils. Journal of Materials Science: Materials in Medicine, 25(1), 11-21.

Riquelme, N., Díaz-Calderón, P., Enrione, J., \& Matiacevich, S. (2015). Effect of physical state of gelatin-plasticizer based films on to the occurrence of Maillard reactions. Food Chemistry, 175, 478-484.

Rostami, A., Mozafari, M., Gholipourmalekabadi, M., Caicedo, H. H., Lasjerdi, Z., Sameni, M., \& Samadikuchaksaraei, A. (2015). Optimization of fluoride-containing bioactive glasses as a novel scolicidal agent adjunct to hydatid surgery. Acta Tropica, 148, 105-114.

Sahraee, S., Milani, J. M., Ghanbarzadeh, B., \& Hamishehkar, H. (2017). Effect of corn oil on physical, thermal, and antifungal properties of gelatin-based nanocomposite films containing nano chitin. LWT-Food Science and Technology, 76, 33-39.

Samadikuchaksaraei, A., Gholipourmalekabadi, M., Erfani Ezadyar, E., Azami, M., Mozafari, M., Johari, B., Kargozar, S., Jameie, S. B., Korourian, A., \& Seifalian, A. M. (2016). Fabrication and in vivo evaluation of an osteoblast-conditioned nanohydroxyapatite/gelatin composite scaffold for bone tissue regeneration. Journal of Biomedical Materials Research Part A, 104(8), 2001-2010.

Sheraz, M. A., Kazi, S. H., Ahmed, S., Anwar, Z., \& Ahmad, I. (2014). Photo, thermal and chemical degradation of riboflavin. Beilstein Journal of Organic Chemistry, 10, 1999.

Sionkowska, A. (2006). Effects of solar radiation on collagen and chitosan films. Journal of Photochemistry and Photobiology B: Biology, 82(1), 9-15.

Tirella, A., Liberto, T., \& Ahluwalia, A. (2012). Riboflavin and collagen: New crosslinking methods to tailor the stiffness of hydrogels. Materials Letters, 74, 58-61.

Tongdeesoontorn, W., Mauer, L. J., Wongruong, S., Sriburi, P., \& Rachtanapun, P. (2012). Mechanical and physical properties of cassava starch-gelatin composite films. International Journal of Polymeric Materials, 61(10), 778-792. 
Uranga, J., Leceta, I., Etxabide, A., Guerrero, P., \& de la Caba, K. (2016). Cross-linking of fish gelatins to develop sustainable films with enhanced properties. European Polymer Journal, 78, 82-90.

Zhang, X., Do, M. D., Casey, P., Sulistio, A., Qiao, G. G., Lundin, L., Lillford, P., \& Kosaraju, S. (2010). Chemical cross-linking gelatin with natural phenolic compounds as studied by high-resolution NMR spectroscopy. Biomacromolecules, 11(4), 1125-1132. 
Fig. 1. FTIR spectra of films with different concentrations of glycerol.

Fig. 2. The main possible interactions resulting from photo-oxidation mechanism in gelatin edible films

Fig. 3. DSC profiles of gelatin films with different concentrations of glycerol at different times of radiation.

Fig. 4. (A) Light microscope photographs of the hADSCs and NIH 3 T3 cells attached on the plastic surface of cell culture flask. (B) MTT results of hADSCs and NIH 3T3 cells after 1, 2, 3, 7 and 14 days incubation with gelatin membrane. Cell viability of negative control (the cells cultured in supplemented DMEM without collagen membrane) was considered as $100 \%$ cell viability. 
Table1 Moisture content, film solubility, water vapor permeability, Tensile strength (TS), elongation at break (EAB) of gelatin films.

\begin{tabular}{|c|c|c|c|c|c|c|}
\hline Films & Thicknes s & $\begin{array}{c}\text { Moisture } \\
\text { content }(\%)\end{array}$ & $\begin{array}{c}\text { Water } \\
\text { solubility }(\%)\end{array}$ & $\begin{array}{c}\text { Water vapor permeability } \\
\left(10^{-12} \mathrm{~g} \times(\mathrm{m} \times \mathrm{s} \times \mathrm{Pa})^{-1}\right)\end{array}$ & EAB (\%) \\
\hline $25 \%-\mathrm{C}$ & $113.6 \pm 1.9 \mathrm{e}$ & $19.7 \pm 0.8 \mathrm{a}$ & $90.2 \pm 0.8 \mathrm{a}$ & $74.3 \pm 0.1 \mathrm{a}$ & $8.6 \pm 0.3 \mathrm{j}$ & $3.5 \pm 1.6 \mathrm{f}$ \\
\hline $25 \%-2 \mathrm{~h}$ & $123.8 \pm 1.6 \mathrm{~b}$ & $8.9 \pm 0.3 \mathrm{e}$ & $37.8 \pm 0.1 \mathrm{~d}$ & $5.8 \pm 0.3 \mathrm{~d}$ & $18.1 \pm 0.1 \mathrm{e}$ & $62.6 \pm 2.2 \mathrm{~d}$ \\
\hline $25 \%-4 \mathrm{~h}$ & $119.4 \pm 1.1 \mathrm{c}$ & $13.2 \pm 0.6 \mathrm{c}$ & $30.7 \pm 0.2 \mathrm{f}$ & $3.7 \pm 0.3 \mathrm{f}$ & $23.1 \pm 0.1 \mathrm{~b}$ & $74.1 \pm 2.0 \mathrm{c}$ \\
\hline $25 \%-6 \mathrm{~h}$ & $115.9 \pm 0.9 \mathrm{~d}$ & $13.1 \pm 0.4 \mathrm{c}$ & $32.4 \pm 0.5 \mathrm{e}$ & $3.0 \pm 0.1 \mathrm{f}$ & $77.8 \pm 0.3 \mathrm{a}$ & $44.0 \pm 1.9 \mathrm{e}$ \\
\hline $50 \%-2 \mathrm{~h}$ & $127.3 \pm 0.8 \mathrm{a}$ & $10.5 \pm 0.9 \mathrm{~d}$ & $40.8 \pm 0.6 \mathrm{c}$ & $9.8 \pm 0.2 \mathrm{~b}$ & $14.9 \pm 0.1 \mathrm{f}$ & $154.5 \pm 3.4 \mathrm{a}$ \\
\hline $50 \%-4 \mathrm{~h}$ & $125.8 \pm 2.1 \mathrm{ab}$ & $10.9 \pm 0.3 \mathrm{~d}$ & $43.1 \pm 0.3 \mathrm{~b}$ & $6.1 \pm 0.1 \mathrm{c}$ & $19.4 \pm 0.4 \mathrm{~d}$ & $125.7 \pm 3.7 \mathrm{~b}$ \\
\hline $50 \%-6 \mathrm{~h}$ & $123.2 \pm 0.6 \mathrm{~b}$ & $15.2 \pm 0.7 \mathrm{~b}$ & $44.5 \pm 0.9 \mathrm{~b}$ & $5.0 \pm 0.1 \mathrm{e}$ & $21.8 \pm 0.2 \mathrm{c}$ & $147.3 \pm 1.4 \mathrm{a}$ \\
\hline
\end{tabular}

Reported values for each film are means \pm standard deviation. Values means followed by the same letter are not significantly $(\mathrm{p}>0.05)$ different according Duncan's multiple range test.

Table 2 Light transmission (\%) and transparency of films obtained with different ratios of gelatin films .

\begin{tabular}{|l|l|l|l|l|l|l|l|l|l|l|l|}
\hline sample & & \multicolumn{7}{|c|}{ Wavelength (nm) } & \multirow{2}{*}{ Transparency } \\
\hline & 200 & 260 & 280 & 350 & 400 & 500 & 600 & 700 & 800 & 0.0044 \\
\hline $25 \%-2 h$ & 0 & 0 & 0 & 0 & 0.7 & 55.4 & 79.7 & 85.6 & 87.8 & 0.0046 \\
\hline $25 \%-4 h$ & 0 & 0 & 0 & 0 & 0.8 & 52.2 & 81.8 & 85.5 & 87.5 & 0.0048 \\
\hline $25 \%-6 h$ & 0 & 0 & 0 & 0 & 0.8 & 59.1 & 81.2 & 85.3 & 86.9 & 0.0040 \\
\hline $50 \%-2 h$ & 0 & 0 & 0 & 0 & 0.2 & 43.3 & 83.3 & 88.2 & 89 & 0.0040 \\
\hline $50 \%-4 h$ & 0 & 0 & 0 & 0 & 0.4 & 50.2 & 82.6 & 87.2 & 89.1 & 0.0047 \\
\hline $50 \%-6 h$ & 0 & 0 & 0 & 0 & 0.6 & 60.2 & 81.9 & 86.5 & 88.1 & 0.0047 \\
\hline $25 \%-$ no uv \& RF & 0.0 & 6.3 & 8.6 & 58.2 & 65.3 & 73.3 & 84.5 & 86.1 & 90.7 & 0 \\
\hline
\end{tabular}




\section{Highlights}

- The UV ray in the presence of riboflavin sensitizer significantly reduced the solubility and WVP of the gelatin films.

- The highest tensilestrength was observed in the treatment $25 \%-6 \mathrm{~h}$ in the presence of riboflavin sensitizer.

- The structural analysis revealed a good interaction between functional groups of riboflavin and gelatin in the $25 \%$-6h film.

- The amount of UV light transmission was zero in all photosensitizer-treated gelatin films. 


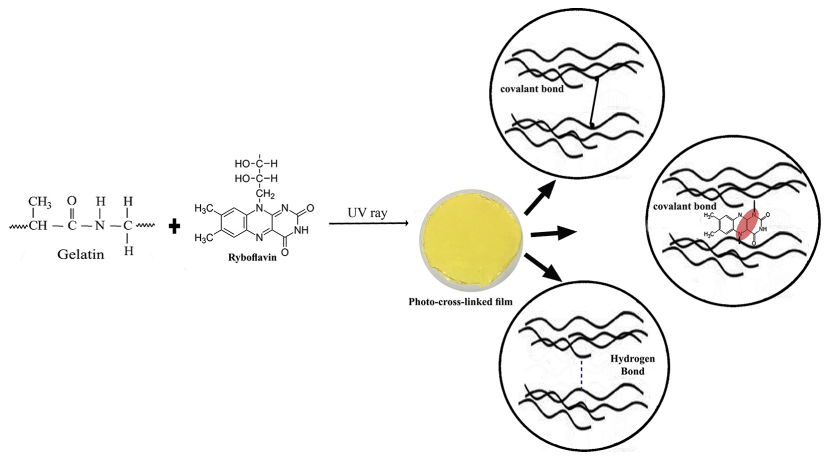

Graphics Abstract 


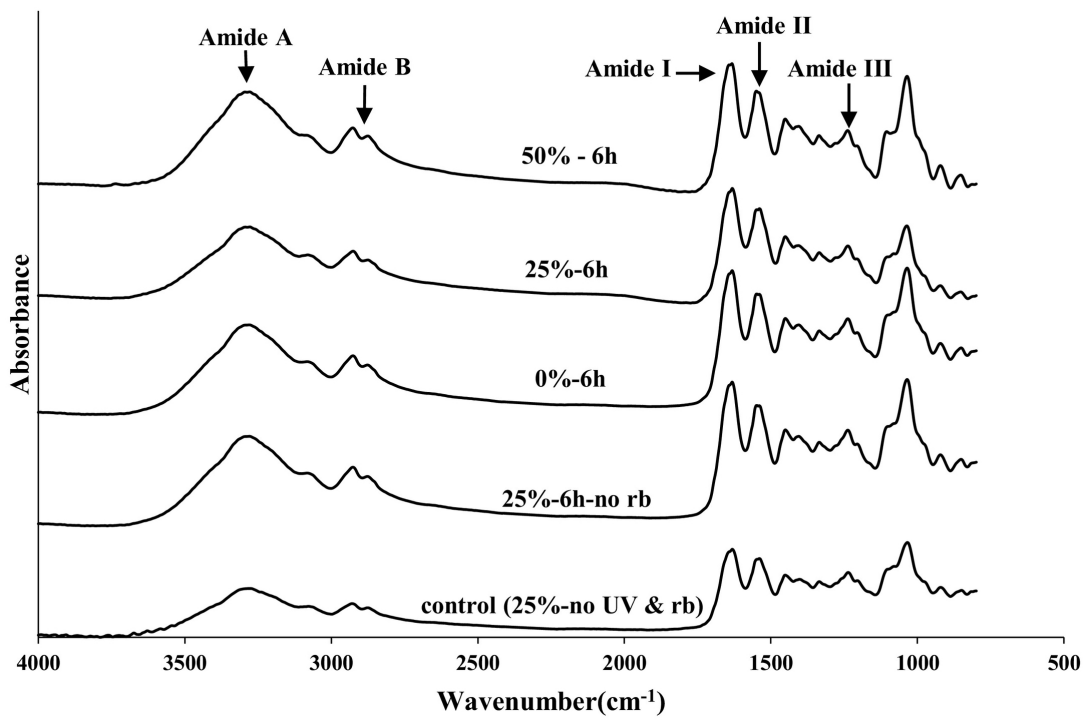

Figure 1 

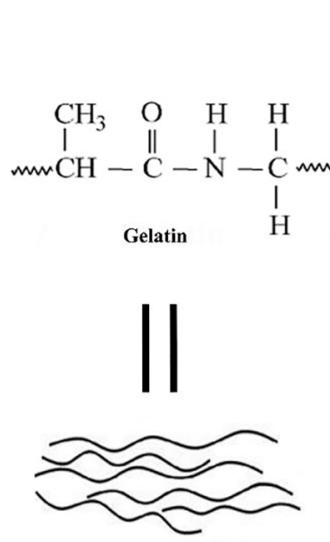
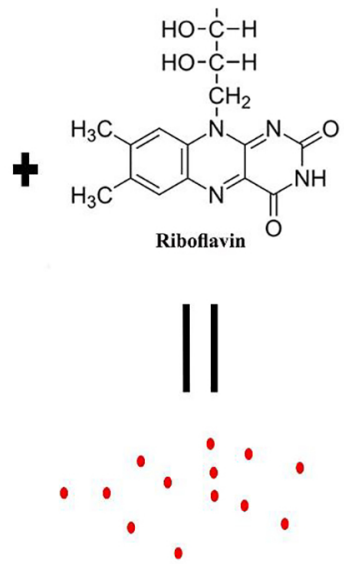
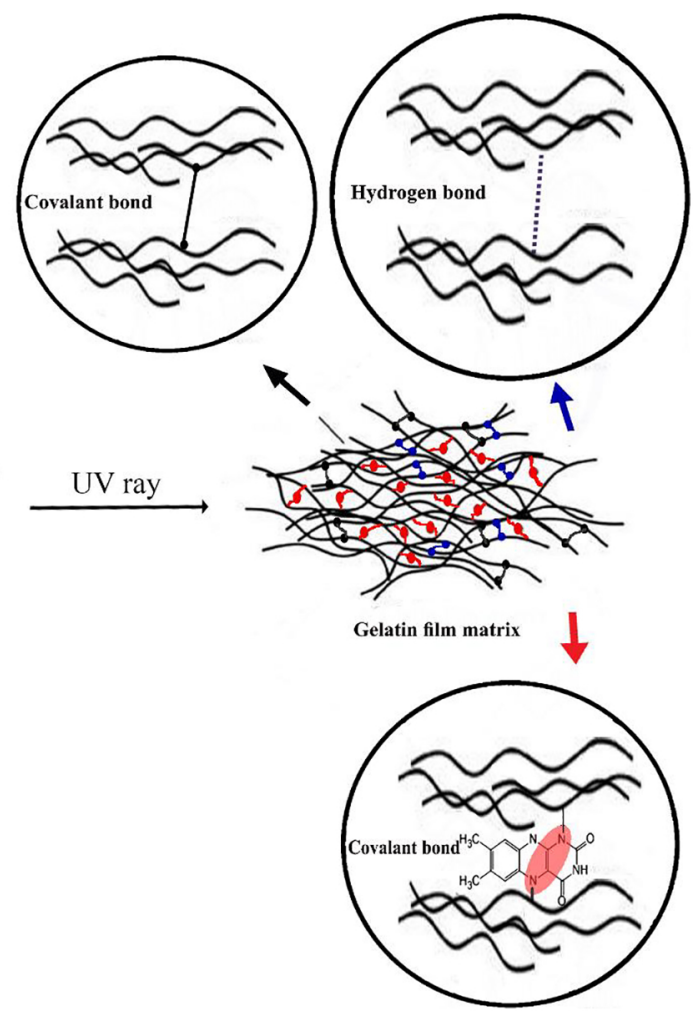

Figure 2 


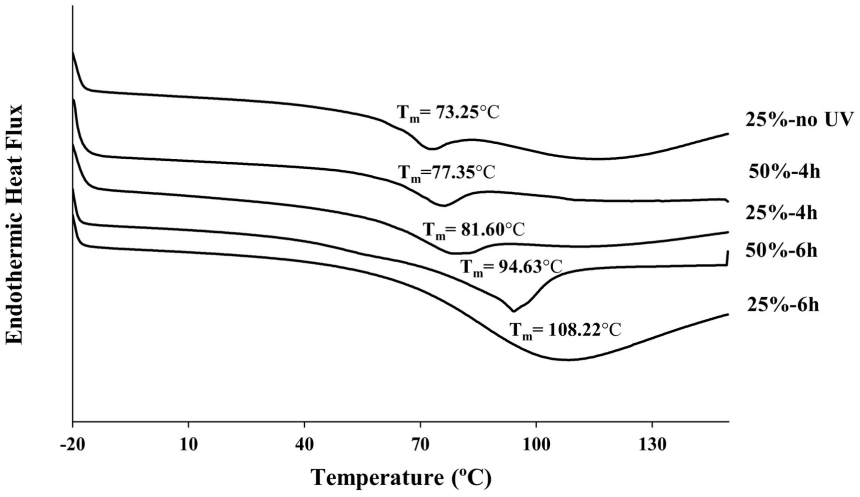

Figure 3 
(A) hADSCs

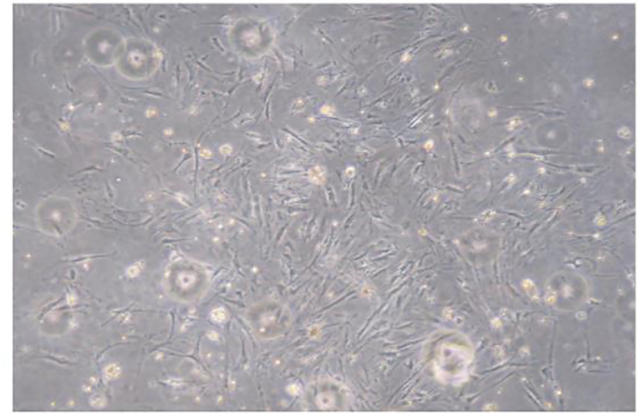

(B)

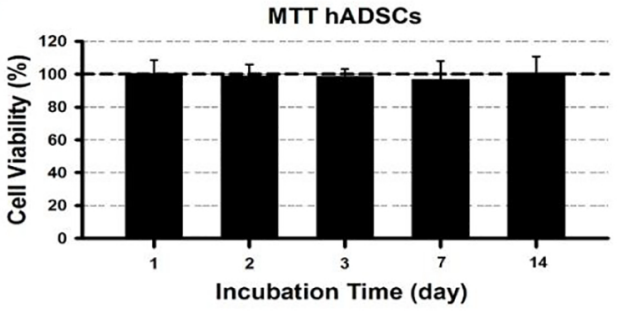

NIH 3T3

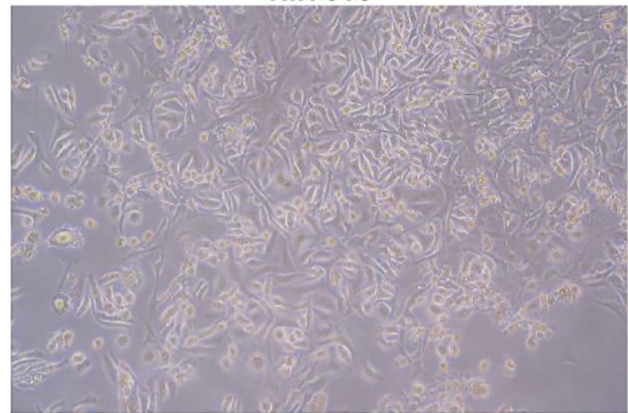

MTT 3T3

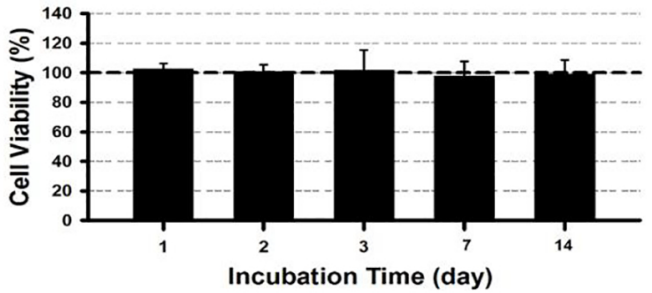

Figure 4 